\title{
MALLU MAGALHÃES E AS NOVAS FORMAS DE CIRCULAÇÃO DA MÚSICA
}

\author{
MALLU MAGALHÃES AND NEW FORMS OF MUSIC DISTRIBUTION \\ MALLU MAGALHAES Y NUEVAS FORMAS DE DISTRIBUCIÓN DE LA \\ $M U ́ S I C A$
}

Tatiana Rodrigues Lima

Doutoranda em Comunicação e Cultura Contemporâneas

Universidade Federal da Bahia

tatianalim@gmail.com

\section{Resumo}

Estudo relacionando a emergência da compositora, instrumentista e cantora brasileira Mallu Magalhães, nos anos de 2007 a 2009, às novas possibilidades de circulação musical proporcionadas por plataformas digitais de internet e telefonia móvel. $\mathrm{O}$ texto aborda as ações de veiculação da compositora no MySpace e a difusão de sua produção em associações com a operadora de telefonia Vivo, mediante a disponibilização de canções em aparelhos celulares e na publicidade convencional. Traz a análise de uma canção que migrou da veiculação na internet e nos telefones móveis para a publicidade televisiva, destacando algumas das possibilidades de trânsitos musicais pelas fronteiras entre os consumos de nicho e massivo proporcionadas pelo cenário comunicacional contemporâneo.

Palavras-chave: Música. Internet. Publicidade.

\begin{abstract}
Study correlating the emergence of Brazilian composer, instrumentalist and singer Mallu Magalhães in the years 2007 to 2009, with the new possibilities of music distribution offered by digital platforms such as the internet and mobile telephony. The text addresses the composers' efforts of placement on MySpace, distribution of her production in association with the phone operator Vivo by releasing songs on mobile devices and traditional advertising. The study also analyses a song that has migrated from running on the internet and on mobile phones to television advertising, highlighting some of the possibilities of transit between the borders of niche and mass consumption offered by the contemporary communication scene.
\end{abstract}

Key words: Music. Internet. Advertising. 


\section{Resumen}

Estudio de la correlación entre la aparición de la compositora, instrumentista y cantante brasileña Mallu Magalhães, en los años 2007 a 2009, y las nuevas posibilidades de circulación de la música proporcionadas por las plataformas digitales de Internet y telefonía móvil. El texto se refiere a las acciones de la compositora en MySpace y difusión de su producción en asociación con la operadora de telefonía Vivo, por la liberación de las canciones en dispositivos móviles y la publicidad tradicional. Aporta el análisis de una canción que ha emigrado de internet y teléfonos móviles a la publicidad televisiva, destacando algunas de las oportunidades de tránsito a través de las fronteras musicales entre el consumo de nicho y de masas que ofrece el escenario de la comunicación contemporánea.

Palabras clave: Música. Internet. Publicidad.

\section{INTRODUÇÃO}

A digitalização da cadeia musical propiciou transformações significativas na forma de produzir, difundir e escutar música. No entanto a interpretação dessas mudanças sob a ótica da ruptura ofuscaria as permanências e adaptações de práticas anteriores à circulação digital da música nas redes telemáticas e suas implicações no âmbito comunicacional. A visibilidade obtida pela jovem compositora e intérprete brasileira Mallu Magalhães, que disponibilizou quatro canções em um perfil musical na rede social MySpace ${ }^{1}$ e obteve em sua página 1,9 milhão de visitas em menos de seis meses (dados de 2007), é um exemplo dos trânsitos da música nas fronteiras entre o consumo de nicho e massivo. O uso de redes sociais e outras plataformas digitais por músicos estreantes que gravam suas produções em home studios ${ }^{2}$ e se valem das plataformas da internet para difundi-las não implica necessariamente na circunscrição desta produção entre os usuários dessas plataformas. Como ocorreu com Mallu, a visibilidade e audibilidade digitais podem alavancar carreiras para além das comunidades virtuais.

\footnotetext{
${ }^{1}$ Disponível em: <http://www.myspace.com/mallumagalhaes>. Criada em: 11/06/2007. Acesso em: 07/03/2010, quando o total de reproduções das canções disponibilizadas pela artista somava 3.488.192. A título de exemplo, no dia de acesso, o perfil de Magalhães contabilizava pouco mais do dobro de reproduções acumuladas até então no perfil de Paul MacCartney (Disponível em: <http://www.myspace.com/paulmccartney>), criado em 09/04/2005, que somava 1.577.769 reproduções.

${ }^{2}$ Os home studios são estúdios de gravação surgidos em meados dos anos 1980, ancorados na tecnologia MIDI (Musical Instrument Digital Interface), criada em 1983. O MIDI é um protocolo, envolvendo hardware e programas (softwares), que permite a simulação digital de um estúdio envolvendo gravadores multicanais, mesa de mixagem e processadores de sinais. O MIDI possibilitou a conexão em rede entre baterias eletrônicas, samplers, sintetizadores digitais e computadores (THÉBERGE, 2006, p.36). O sistema barateou os custos de gravação, uma vez que a produção musical passava a ocorrer sem os grandes investimentos anteriormente custeados majoritariamente pelas gravadoras.
} 
Para introduzir a discussão, são narrados alguns fatos da trajetória musical de Mallu Magalhães. Destaco apenas os acontecimentos que ancoram as reflexões em torno dos aspectos da cultura musical tratados nas seções seguintes.

Em 2007, ao completar 15 anos, Mallu Magalhães recebeu como presente de aniversário dos pais a quantia de $\mathrm{R}$ \$ 1,5 mil. A jovem utilizou o dinheiro para gravar quatro canções de sua autoria - Tchubaruba, Don't You Leave Me, J1 e Get to Denmark - num pequeno estúdio que oferecia serviços de gravação de CDs, demos e registros ao vivo, o Lúcia no Céu, em São Paulo. Em seguida, colocou as gravações em um perfil musical no MySpace ${ }^{3}$. A rede social criada em 2003 nos EUA - que ganhou versão em português justamente em 2007 - promoveu o perfil da cantora e compositora internamente, em banner exibido em espaços reservados para publicidade de suas páginas. Mídias massivas não foram acionadas nesse primeiro momento, mas dois tipos de interesse concorreram para a divulgação da cantora e compositora em banners na plataforma. O MySpace havia aberto uma representação no Brasil e tinha interesse em ampliar sua receita, acessos (views) e número de perfis criados no País, o que implicava em destacar mais o conteúdo produzido por brasileiros, a fim de atrair o público-alvo. Mallu tinha amigos ligados à representação brasileira da plataforma, o que facilitou a sua inclusão entre os perfis locais destacados ${ }^{4}$.

Também através de contatos pessoais, Mallu recebeu o primeiro convite para se apresentar profissionalmente. Por conta da mobilização de interesses no MySpace e da presença de alguns jornalistas em sua estreia nos palcos, em janeiro de 2008, a compositora "ganhou destaque nos principais jornais, revistas e sites noticiosos do país" (ANTENORE, 2008, p. $73)^{5}$. Em seguida, Mallu participou de alguns festivais de música independente como Jambolada, Eletronika, MADA, Coquetel Molotov, Gig Rock e de um festival de cunho mais comercial, o Planeta Terra.

\footnotetext{
${ }^{3}$ Pelo fato de a abertura do perfil ter ocorrido em 2007 e a pesquisa que resulta neste artigo ter se iniciado em 2009, não é possível discutir os aspectos plásticos da página de Mallu Magalhães na época da divulgação das faixas, uma vez que conteúdo e design da página sofreram alterações. Composições lançadas na época são analisadas com base em suas versões disponíveis no primeiro álbum da cantora.

${ }^{4} \mathrm{~A}$ informação sobre o banner foi obtida durante reunião do grupo de pesquisa Audiosfera. A representação do MySpace no Brasil foi fechada em 2009, quando a News Coorporation, proprietária da plataforma, determinou a centralização das atividades de captação de publicidade no Brasil pelo escritório nacional de outra empresa de sua propriedade, a Fox. Em função disso, não foi possível obter mais detalhes sobre a decisão de promover o perfil de Mallu em banners do MySpace.

Alguns exemplos: entrevista na Trip publicada em 05/03/2008 [Disponível em: <http://revistatrip.uol. com.br/revista/salada/peso-leve.html >. Acesso em 23/05/2010.]; matéria na edição de março na versão brasileira da revista mensal RollingStone [Disponível em: <http://www.rollingstone.com.br/edicoes/18/textos/1966/>. Acesso em 23/05/2010]; além de capas dos segundos cadernos do Jornal do Brasil e Folha de S. Paulo, entre outras publicações.
} 
Procurada por cinco gravadoras, as transnacionais Warner, EMI, Sony-BMG, Universal, e a independente brasileira Deckdisc, para lançar um álbum de estreia, recusou todas as propostas (ANTENORE, 2008, p. 78). Produziu um CD independente e editou as composições pelo selo Agência de Música. Conforme o site oficial da cantora,

Mallu entrou no estúdio AR no Rio de Janeiro para gravar suas músicas com uma mesa analógica inglesa da EMI, dos estúdios Abbey Road, gravadores analógicos de fita e microfones raros dos anos 60 estiveram à disposição para captar essa atmosfera. A produção ficou a cargo de Mário Caldato Jr., que já trabalhou com artistas como Jonh Lee Hooker, Beck e Björk, e o álbum foi lançado de forma independente pelo selo Agência de Música em novembro de $2008 .^{6}$

Antes da chegada do disco em suporte físico às lojas, a operadora de telefonia Vivo fechou contrato com a compositora, a fim de disponibilizar as faixas do CD, intitulado Mallu Magalhães, para os usuários de seu sistema de telefonia móvel. Uma matéria do jornal Folha de S. Paulo, em 20/10/2008, registra o momento:

a cantora lançou seu primeiro disco em uma ação de marketing com uma operadora de celular, que está vendendo cada faixa por $\mathrm{R} \$ 1,99 \mathrm{em}$ seu site. Além disso, cinco modelos de telefone estão sendo lançados com o álbum completo armazenado na memória. Em novembro, o CD chega às lojas. $(\text { CASTRO, 2008) })^{7}$

A Vivo também negociou o uso da canção $J 1$ em comerciais para a televisão aberta e por assinatura. Nessas peças publicitárias, de maior exposição massiva, a canção estava desvinculada da imagem da compositora, uma vez que era trilha sonora do material publicitário voltado ao consumo de telefonia celular.

Mesmo com o êxito de audição e downloads gratuitos no MySpace e o surgimento de uma alternativa de arrecadação com direitos autorais mediante os contratos com a Vivo, a compositora também se valeu de um produto tradicional, o álbum em CD, como suporte para circulação de sua produção. Isso demonstra que, no atual panorama da cultura musical, novas possibilidades de circulação convivem com modelos anteriores. Como ocorreu com Mallu Magalhães após a emergência, muitos músicos optam por uma carreira independente das majors ${ }^{8}$ da indústria fonográfica, mas continuam a lançar discos em suporte físico.

\footnotetext{
${ }^{6}$ Disponível em: <http://www.agenciademusica.com.br/mallumagalhaes/site/index.php\#/Sobre>. Acesso em: 05/06/2010.

${ }^{7}$ Notícia disponível em: <http://www1.folha.uol.com.br/folha/ilustrada/ult90u458008.shtml>. Acesso em: 07/06/2010.

${ }^{8} \mathrm{O}$ termo major (maior ou principal, em inglês) é comumente utilizado pela crítica musical para se referir às gravadoras transnacionais com braços corporativos em outros ramos da indústria da comunicação e do entretenimento, como cinema, televisão aberta e a cabo, internet, fabricação de equipamentos etc. Podem-se citar
} 
Com o retorno financeiro dos contratos com a Vivo, Mallu produziu um DVD em suporte físico e o lançou também pela gravadora independente Agência de Música (ANTENORE, 2008), mais uma adoção de um formato de circulação tradicional pela compositora independente. Somente no segundo CD, que igualmente leva seu nome, a cantora vinculou-se formalmente a uma empresa da indústria fonográfica tradicional. O álbum foi lançado em 2009, pela Sony Music, em parceria com selo indie Agência de Música, ao qual Mallu continuou vinculada.

No caso da cantora, o êxito na circulação gratuita via internet e na associação com uma empresa de telefonia para a circulação musical remunerada conferiram-lhe respaldo para negociar posteriormente com uma representante da indústria fonográfica convencional. Os fatos acima apontam que não cabe advogar o fim da indústria musical, mas sim falar de um momento de reconfiguração no qual o poder da indústria fonográfica confronta-se com o crescimento da influência de outras instâncias que passam a participar da produção, comercialização e circulação da música - no caso aqui estudado, a produção digital mais barata financiada pela própria autora musical, a comercialização associada à telefonia, bem como a circulação associada ao MySpace, à publicidade e à telefonia móvel.

\section{A MÚSICA DE MALLU MAGALHÃES E AS NOVAS FORMAS DE CIRCULAÇÃo}

Para entender o posicionamento de Mallu Magalhães na cultura musical, é necessário atentar também para as configurações plásticas das suas canções. Em que medida a produção da compositora tensiona os padrões da música massiva? Em quais aspectos reitera o formato canção, facilitando sua penetração ampla?

Há uma diferença entre a produção musical disponibilizada pela cantora inicialmente em seu perfil no MySpace e aquela que passou a circular nas plataformas da Vivo e em seu primeiro CD independente. As versões de Tchubaruba, Jl e Get to Denmark que foram comercializadas no site da Vivo e lançadas em disco têm um padrão de qualidade bastante superior àquelas que provocaram o boom de acessos no MySpace. Nas versões gravadas no

como majors da atualidade as gravadoras Universal, EMI, Sony-BMG e Warner. As mega-estruturas das majors dificultaram o remanejamento de seus modelos de negócio com o advento da internet. O setor fonográfico da maioria das majors enfrenta atualmente uma crise decorrente da redução da arrecadação em direitos autorais e em vendas de CDs e DVDs e atribuem a situação ao surgimento da cultura do download. Como alternativas, as majors têm negociado com seus contratados percentuais sobre os lucros em shows, já que os mega-espetáculos e turnês de astros pop como Madonna, U2, Rolling Stones etc. movimentam hoje mais dinheiro do que a venda de discos. Recentemente, estão oferecendo também seus produtos para download pago em sites próprios e lojas virtuais. 
estúdio AR percebe-se uma produção rebuscada em termos de arranjo, com exploração da dinâmica e interação entre instrumentos; na forma como soam os instrumentos (volumes em que são mixados, timbres e usos de efeitos), entre outros elementos que dependem tanto da qualidade técnica do estúdio quanto da experiência do produtor musical ${ }^{9}$.

No próprio texto sobre a compositora publicado em seu site oficial, alguns músicos produzidos por Caldato Jr. - que além de gravar com grandes nomes da música mundial produziu CDs de "medalhões" da música nacional ${ }^{10}$ - são elencados, como forma de agregar capital simbólico ao currículo de Mallu. Os artistas produzidos por Caldato Jr. têm forte marca autoral em suas obras; embora sejam músicos de sucesso mundial ou nacional, não são associados ao pop de fácil consumo, mas sim a marcas de estilos personalizados, mesmo quando filiados a gêneros musicais de ampla penetração. A variada lista de produções de Caldato Jr. é índice do prestígio, profissionalismo e da capacidade do produtor de traduzir em termos sonoros diferentes projetos e propostas musicais.

Infere-se que há padrões de qualidade sonora distintos entre o que pode ser um êxito no MySpace - plataforma na qual os quase dois milhões de views obtidos por Mallu ocorreram quando as gravações disponíveis eram originárias da produção mais amadora no estúdio Lúcia no Céu - e as gravações comercializadas no site da Vivo e no CD da cantora. Mesmo sem vínculo com uma gravadora tradicional, a compositora investiu em qualidade de configuração sonora no momento de ampliar e profissionalizar sua circulação. Todavia vale ressaltar que o apuro técnico na segunda produção não implicou numa mudança radical de repertório, visando à aceitação massiva. Em comum às duas esferas estão as três composições que migraram do perfil de acesso gratuito para as plataformas digitais comercializadas e para a publicidade, ou seja, o trabalho autoral da compositora - ela assina sem parcerias todas as letras e músicas de seu primeiro CD - que inicialmente teve boa aceitação entre os internautas e posteriormente mostrou-se adequado à demanda da Vivo.

Entre as três composições que permaneceram na segunda gravação, a escolhida para figurar em comerciais de TV, ou seja, a que teve maior penetração massiva, aproxima-se da gramática cancional. $J 1$ é uma canção com 3 minutos e 48 segundos de duração, extensão adequada à execução em mídias massivas como o rádio. A voz da cantora soa em volume acima dos demais instrumentos, uma opção de mixagem que facilita a compreensão do discurso linguístico e é comum nos sucessos massivos.

\footnotetext{
${ }^{9}$ A análise da configuração plástica do CD renderia um artigo à parte, mas não está no foco deste texto.

${ }^{10}$ Ver discografia completa do produtor disponível em: <http://marioc.com/pdf/discography. pdf>. Acesso em: 08/06/2010.
} 
A repetição do refrão por cinco vezes ao longo da canção contribui para a memorização e ampla penetração da canção. No universo pop, o refrão é o momento de maior engajamento entre o ouvinte e a música, possibilitando inclusive à audiência cantar junto. Roy Shuker o define como "padrão melódico ou rítmico facilmente memorizado. O refrão atrai e 'prende' o ouvinte, fazendo-o querer escutar o restante da canção e, mais importante, diversas vezes" (SHUKER, 1999, p.236).

Apesar da forte presença do refrão em $J 1$, a canção não tem uma estrutura simples de alternância entre parte A, refrão e parte B. A inclusão de uma terceira melodia vocal na parte A, como gancho para as repetições do refrão, confere distinção com relação ao formato cancional mais simples, embora não estabeleça um confronto mais direto com o formato cultural, como o que é verificado em outras faixas do CD da cantora. A faixa de abertura, You know you've got, por exemplo, é marcada pela contrastante variação de andamentos e exploração da dissonância em alguns ataques de piano; na psicodélica $O$ preço da flor, a voz é mixada no mesmo volume dos instrumentos.

$\mathrm{Na}$ esfera do discurso linguístico, a letra de $J I$ explora a ambiguidade de sentidos, denunciada no próprio título, que permite interpretações variadas conforme o repertório do ouvinte. Os versos iniciais da parte $\mathrm{A}^{11}$ tanto podem ser conectados ao universo adolescente, compondo como sujeito da enunciação uma jovem (os vocais são femininos e o eu-lírico está em primeira pessoa) que tenta escrever uma mensagem revelando seus sentimentos a alguém a quem deseja se declarar, quanto podem sugerir a situação da própria letrista em processo de composição cancional, tratando de forma metalinguística da dificuldade de compor os versos para a canção. A inclusão de um verso com uma expressão sem significado dicionarizado (Papapapa) reforça os sentidos de dificuldade de comunicação que se aplica a ambas as situações. Na estrofe ${ }^{12}$ a ambiguidade permanece, pois a ideia de ouvir melhor tanto se aplica a um personagem interno, objeto do desejo do narrador, quanto à própria canção.

Do ponto de vista da circulação da canção, a opção pelo canto em inglês tanto restringe as possibilidades de popularização massiva da canção no país de origem da cantora quanto indica uma posição de que a total compreensão da letra é menos importante do que sua interação com os sentidos sonoros e um direcionamento ao nicho de ouvintes da folk music, gênero cujos “clássicos" são associados à música norte-americana dos anos 1960. A produção utilizando

\footnotetext{
11 "Well I take a notebook / I walk away / This paper tries to make me say", seguidos do refrão "Papapapa / Will I have to try again / Papapapa / For your to understand".

12 "I should have known you better / I should have heard you more / before / I write that letter / I should have done what / I've been looking for".
} 
"uma mesa analógica [...], gravadores analógicos de fita e microfones raros dos anos 60"13 reforça a referência ao período áureo do folk, cultuado pelos amantes do gênero, que se constituem num nicho, reforçando o direcionamento da compositora a esse segmento de ouvintes. Traçando um paralelo entre a sonoridade vintage da gravação e recentes discussões sobre a revalorização do vinil na cultura musical contemporânea, pode-se dizer que os equipamentos analógicos utilizados na gravação servem também como "elementos de distinção dentro de um universo com tendências homogeneizantes como o da música massiva" (SÁ, 2009, p.65). Ainda aproximando a opção de gravação com as reflexões de Simone Sá, observase que "o que está em jogo não é a nostalgia, entendida como um retorno 'acrítico' ao passado, mas a intensidade da experiência, que permite o link com outras pessoas, lugares e momentos" (2009, p.66). A sonoridade obtida na segunda gravação em estúdio da canção $J 1$, portanto, conecta a música de Mallu Magalhães a valores como sofisticação, não repetição de padrões segundo critérios comerciais, conhecimento histórico-musical, entre outros índices de autenticidade, em oposição à cooptação aos padrões massivos.

A opção pela letra em inglês também aciona valores de não-rendição ao consumo fácil, ao tempo em que não inviabiliza de todo a penetração da canção, se levarmos em conta que os vocais suaves, mixados com volume superior ao dos demais instrumentos, são característicos das canções pop, independentemente do idioma. O verso "Papapapa", no refrão, é potencializador dos sentidos de impossibilidade de comunicação de que trata a letra, ao tempo em que convida o ouvinte que não domina o inglês a cantar junto. Os aspectos descritos acima contribuem para que a canção se situe no entre-lugar do nicho e do massivo. São coerentes com a emergência singular da cantora e seu trânsito entre as fronteiras e plataformas de modelos variados.

\subsection{A circulação da música em plataformas digitais}

Em Nuevas tecnologias, música y experiencia, George Yúdice observa que conquistar a preferência das massas não é pré-requisito para a circulação musical contemporânea.

$\mathrm{Na}$ 'época da reprodução digital', das redes que se valem dela e dos mercados de nicho que se abrem a partir dela, é questionável o uso da noção de 'massa' [...] As novas tecnologias afetaram a maneira como a música incide na organização social, desde os tradicionais clubes de melômanos a blogs, chats e sites de Internet, nos quais gostos musicais são um componente crucial nos perfis que atraem as pessoas a se relacionarem com

\footnotetext{
${ }^{13}$ Disponível em: <http://www.agenciademusica.com.br/mallumagalhaes/site/index.php\#/ Sobre>. Acesso em: 05/06/2010.
} 
seus congêneres, os quais podem viver à distância de dobrar uma esquina ou a vinte mil quilômetros, do outro lado do mundo ${ }^{14}$. (YÚDICE, 2007, p.2223)

A observação coloca em pauta músicas midiáticas que não são consumidas massivamente e ainda assim encontram no ambiente contemporâneo formas de sustentabilidade de grande interesse do ponto de vista da comunicação ${ }^{15}$. Ao sair da esfera da oralidade para o da fixação mediante o aparato tecnológico digital (as gravações em variados formatos e suportes materiais ou virtuais) tais expressões dispõem de uma gama de possibilidades de circulação, de forma que podem ir ao encontro do seu público com mais facilidade do que no período anterior à digitalização.

Foi o que ocorreu com as faixas disponibilizadas inicialmente por Mallu Magalhães no seu perfil do MySpace. A difusão inicial ocorreu em plataformas da internet, mediante ações de ouvintes-navegadores que indicaram e recomendaram as canções, constituindo-se nos primeiros críticos e divulgadores das composições.

No caso de Mallu Magalhães, a qualidade das gravações disponibilizadas no MySpace gerou 1,9 milhão de visitas iniciais do perfil da compositora, mas, para ter suas canções comercializadas em outra plataforma digital, o site da Vivo, as canções passaram por uma produção tecnicamente mais rebuscada no estúdio AR.

Certamente a audiência inicial obtida pela cantora no MySpace foi um dos fatores que fizeram a operadora de telefonia decidir vincular sua marca à produção de Mallu Magalhães. O talento, a criatividade (neste caso a criação musical), o êxito em um dispositivo de comunicação surgido recentemente e a juventude como indicadora de perspectivas de mudanças e inovações estão em consonância com a valorização da tecnologia de ponta que é um dos pilares do marketing da telefonia móvel.

O VT de 30 segundos da Vivo, em que o trecho inicial da canção de $J 1$ é utilizado como trilha sonora, reitera as inferências acima. Na peça, jovens figuram em cenas inusitadas. $\mathrm{Na}$ primeira sequência, um rapaz passeia com seu cão, mas em vez de fazê-lo caminhar, o arrasta

\footnotetext{
${ }^{14}$ Do original em espanhol: "En la 'época de la reproducción digital', de las redes que se valen de ella y los mercados de nicho que se abren a partir de ella, es cuestionable el uso de la noción de 'masa' [...] Las muevas tecnologías han afectado a la manera en que la música indice en la organización social, desde los tradicionales clubes de melómanos a los blogs, chats y sitios en Internet en los que los gustos musicales son un componente crucial de los perfiles que atraen a la gente a relacionarse con sus conténeres, los cuales pueden vivir a la vuelta de la esquina o a veinte mil kilómetros al otro lado del mundo". (Tradução livre).

${ }^{15}$ A recente fragmentação do consumo proporcionada pela digitalização da música e sua circulação em redes telemáticas é tema de estudos tanto da área comunicacional quanto em perspectivas ligadas à economia e ao marketing, a exemplo da teoria da cauda longa (ANDERSON, 2006).
} 
num carrinho, uma situação não-convencional, acionando sentidos ligados à não repetição de uma rotina, à criatividade. A frase "Eu tenho um plano mais adequado" reforça a imagem de fuga aos hábitos comuns, de diferenciação em relação aos demais. Na sequência seguinte, uma jovem interrompe o treino de boxe para fazer carinho no boneco sparring de borracha. Os gestos da garota, de afetividade em lugar dos golpes, são associados à frase "Eu sempre tenho promoções", sugerindo que o produto vendido procura agradar o cliente, como faz a personagem. Em seguida, uma garota usa uma cama elástica para colher uma fruta no alto de uma árvore e a frase exibida é "Eu tenho aparelhos modernos", ligando a modernidade tecnológica ao artifício usado pela jovem. Depois duas garotas dançam, pulam e parecem comemorar a mensagem do texto: "Eu ganho bônus até quando me ligam". Por fim, a frase "Eu sou respeitado" é exibida numa sequência em que um jovem de cabelos encaracolados está sentado numa cadeira de barbeiro, mas não tem seus cachos atingidos pela tesoura. $\mathrm{Na}$ sequência final, um rapaz manipula um telefone celular e a locução afirma "Eu sou pré, eu sou vivo", revelando finalmente a imagem do produto, o aparelho, e a modalidade de serviço oferecido, a ligação pré-paga.

Em nenhum momento é explicitada a autoria da canção que serve de trilha sonora para o VT, mas é possível supor que uma parte do público-alvo da peça, os jovens consumidores de celulares com serviço pré-pago, teria informações sobre a cantora, cuja produção, naquele momento, já vinha tendo uma divulgação ampla. Para os telespectadores que não tinham informações sobre ela, a voz com timbre de adolescente serve como elemento de identificação, associada às imagens acima descritas, todas envolvendo personagens com biotipo juvenil ${ }^{16}$.

Alguns aspectos valorados positivamente no VT, como diferenciação, criatividade, estética dissociada dos padrões convencionais, aplicam-se também à trajetória de Mallu Magalhães. Talento e inovação juvenil em consonância com a ideia de acesso à tecnologia de ponta da telefonia aproximam Mallu dos objetivos de marketing da Vivo. Descontextualizados do restante da canção, os versos da estrofe e refrão ouvidos durante os 30 segundos do comercial em nada remetem à dificuldade da comunicação - o que transtornaria o discurso da Vivo.

Uma pesquisa empírica de audiência sobre a associação entre o comercial de TV e a autora da canção que serviu como trilha sonora não faz parte dos propósitos deste artigo. A descrição

\footnotetext{
${ }^{16}$ Em texto sobre o gadgets, entretenimento e juventude, em que são analisados comerciais de telefones celulares, Rocha, Pereira e Balthazar afirmam que "juventude é um fenômeno social - reflexo e produto de um imaginário coletivo, influenciando marcadamente a maneira como os indivíduos constroem suas identidades e fazem suas escolhas - que agrega, a um só tempo, valores como modernidade, felicidade, sociabilidade, amizade e liberdade" (2010, p.9).
} 
acima tem como objetivo registrar que o caso de Mallu Magalhães é um exemplo da progressiva perda de poder de triagem das gravadoras e demais instâncias de circulação convencional como rádios e lojas físicas na cultura musical. Permite inferir que a música midiática produzida com pretensões de conquistar ouvintes de nicho é potencialmente massiva. Uma vez ingressando nas plataformas de circulação digital, o interesse de um grande número de ouvintes, mediante esquemas de divulgação paralelos ao da indústria musical, como a recomendação de fãs em e-mails pontuais, listas de discussão, blogs, chats etc. ${ }^{17}$, pode levar ao ingresso posterior em formas massivas de divulgação.

\section{CONSIDERAÇÕES: DA MÚSICA DE MALLU AO CENÁRIO MUSICAL CON- TEMPORÂNEO}

No caso exposto, percebemos que a circulação digital da produção de Mallu Magalhães, que a fez ser considerada pela imprensa massiva um "fenômeno da internet" antes do lançamento de um álbum, despertou o interesse da indústria fonográfica e da operadora de telefonia. $\mathrm{O}$ ingresso da cantora no circuito de festivais precedeu a gravação do $\mathrm{CD}$, porém os registros das canções com apuro técnico, implicando inclusive no uso de gravadores analógicos, para o álbum independente Mallu Magalhães, em 2008, abriram portas para a captação de recursos que também permitiram a manutenção da carreira da cantora e compositora. É preciso considerar também que, ao decidir produzir um primeiro $\mathrm{CD}$, a ideia de compor um álbum como uma obra que plasma um momento de produção musical, representando uma fase criativa, parece ter sido a motivação principal da compositora. A comercialização das faixas no site da Vivo não era o objetivo central da produção, mas apresentou-se como uma boa alternativa para a sustentação do projeto. O fato de a cantora ter lançado um segundo álbum no ano seguinte reforça a afirmação de que, em sua trajetória, o formato tem relevância.

A reconfiguração tecnológica na esfera musical torna, portanto, permeável a fronteira entre os conceitos de música de nicho, ou música underground, e a música mainstream. Essas delimitações perdem o caráter dicotômico, à medida que se observava uma maior mobilidade entre os dois eixos, como ocorreu com Mallu Magalhães.

A emergência de Mallu Magalhães ilustra de forma oportuna as atuais instabilidades de fronteiras, pelos seguintes motivos: 1) a compositora disponibilizou no MySpace canções

\footnotetext{
${ }^{17}$ Evidentemente, grande parte da música midiática produzida fora da indústria fonográfica convencional não obtém visibilidade massiva, mas a autossustentação e a sucessão de lançamentos gera uma divulgação cumulativa.
} 
num perfil em que classifica sua produção no gênero folk music, que não faz parte dos gêneros de música popular brasileira urbana; 2) a proposta de lançamento de canções em inglês por uma brasileira pode ser considerada um fator restritivo da sua circulação musical do ponto de vista massivo e tanto o canto em inglês quanto a filiação ao folk direcionam a produção da cantora a um nicho de ouvintes que dominam o idioma e apreciam o gênero; 3) os 1,9 milhão de acessos às canções de Mallu no perfil do MySpace ocorreram antes que a produção obtivesse divulgação nos meios de comunicação massivos, mostrando que é possível obter circulação ampla sem acionar a mídia tradicional; 4) a marca de quase dois milhões de acessos era um patamar antes obtido por artistas de consumo massivo, demonstrando que as fronteiras entre as duas esferas de consumo são mais permeáveis do que no período anterior à circulação digital da música em redes telemáticas, quando o músico de nicho enfrentava maiores dificuldades na distribuição musical; 5) embora tenha fechado contrato com uma grande empresa para a comercialização de suas canções, Mallu Magalhães não se vinculou inicialmente a uma companhia cuja finalidade é a produção fonográfica e sim a uma empresa de telefonia móvel; isso sugere que não estamos diante do fim da circulação musical nos moldes massivos, mas de uma reconfiguração em que a indústria fonográfica vem perdendo espaço para outros setores industriais da comunicação e do entretenimento.

Os estudos comunicacionais sobre música têm incluído as produções de nicho e toda a cadeia das expressões ligadas ao underground desde finais dos anos 1970, com o já referencial Subculture: the meaning of style (HEBDIGE, 2002 ${ }^{18}$ ). Gêneros considerados de nicho, anteriores à digitalização e às redes telemáticas, como o punk rock, cuja proposta de "do it yourself" e a identificação com os ideais anarquistas gerou a produção de fanzines e de gravações caseiras em fita cassete ${ }^{19}$, e outras ações descentralizadas, sempre estiveram em foco nas abordagens comunicacionais da música, em publicações filiadas aos estudos culturais. Pode-se afirmar que as plataformas digitais e redes telemáticas potencializaram as interações do underground. Como sintetiza Simone Sá,

são bandas que fazem sucesso graças a downloads na internet, sem terem lançado um único CD. São blogs antecipando tendências musicais antes das revistas especializadas. São versões sucessivas de videoclipes feitos por fãs. São redes sociais [...] que criam comunidades a partir da troca de arquivos sonoros pela internet. Sem falar nos estúdios caseiros, nos podcastings, no crescimento exponencial de gravadoras independentes e de vendas de música

\footnotetext{
${ }^{18}$ Primeira publicação em 1979, na Inglaterra, pela editora Methen \& Co. Ltd.

${ }^{19}$ Tanto os fanzines quanto os cassetes circulavam pelos correios, mas vale notar que as tiragens e números de cópias magnéticas ficavam entre 1 mil e 5 mil exemplares. Hoje a divulgação da música de nicho em redes telemáticas gera quantidades bastante superiores de page views, downloads e escutas em streaming.
} 
por unidade por meio da rede [...]. Tudo isso, em conjunto, chamando-nos a atenção para a revolução que a cibercultura introduziu no circuito de produção, circulação e consumo musical em pouco mais de uma década. $(2009$, p.45)

No caso de Mallu Magalhães, uma produção independente se valeu de formas de circulação alternativas tanto no modelo todos-todos, mediante seu perfil no MySpace, quanto num modelo um-todos, com a venda de suas canções no site e nos celulares da Vivo.

Atualmente, os sistemas de publicação e gerenciamento de conteúdo em redes telemáticas são apropriados tanto por artistas e fãs do mainstream quanto do underground. É preciso então levar em conta não apenas a procedência dos suportes digitais utilizados e sim os seus usos. Em artigo sobre $O$ novo mainstream da música regional, Felipe Trotta e Márcio Monteiro (2008) chamam atenção, por exemplo, para gêneros gestados fora da indústria fonográfica convencional, como o axé music, "brega"(sic), reggae e forró eletrônico, cujo êxito comercial ultrapassa "estética e quantitativamente os limites da classificação independente" (2008, p.1) em suas regiões, transitando para o consumo nacional e até global. Os gêneros citados estão esteticamente atrelados à repetição de fórmulas de sucesso, como ocorre no mainstream, mas muitas vezes passam ao largo da indústria fonográfica no momento de sua emergência. Ao obter sucesso de público, alguns mantêm-se fora das gravadoras, outros se vinculam a gravadoras convencionais e passam a circular em mídias massivas convencionais ${ }^{20}$.

Estudos futuros pautados em parâmetros comunicacionais podem aprofundar melhor a tensão atual entre underground e mainstream e sua circulação em mídias massivas e pós-massivas, uma vez que o campo da comunicação abarca possibilidades de debater as valorações ideológicas, econômicas e sociológicas associadas à música e sua configuração plástica. Tal discussão demanda análises verticalizadas de outros produtos e seus contextos, uma vez que as reconfigurações contemporâneas requerem uma atenção dos pesquisadores de música e comunicação tanto para o uso de mídias pós-massivas por músicos oriundos de mídias de função massiva ${ }^{21}$ e seu efeito na produção de sentido das produções musicais, quanto para o

\footnotetext{
20 "Numa complexa engrenagem de produção musical articulada com canais de difusão radiofônica e uma intensa identificação regional baiana, a axé music se desloca do cenário circunscrito e 'independente' do carnaval de rua de Salvador para ocupar fatias significativas do mercado de música nacional, configurando-se como um dos três principais gêneros musicais do início da década de 1990." (MONTEIRO; TROTTA, 2008, p.6).

${ }^{21}$ Lemos compreende a função massiva como "um fluxo centralizado de informação, com o controle editorial do pólo da emissão, por grandes empresas em processo de competição entre si, já que são financiadas pela publicidade. Busca-se, para manter as verbas publicitárias, sempre o hit, o sucesso de 'massa' [...] para pessoas que não se conhecem, que não estão juntas espacialmente e que assim têm pouca possibilidade de interagir" (LEMOS, 2009, p.5).
} 
caráter provisório e tensivo das classificações de mainstream e underground, por conta da maior visibilidade obtida pelas produções de nicho nas redes telemáticas.

No panorama contemporâneo deve-se estar atento, portanto, à instabilidade e ao caráter provisório das classificações de massivo, de nicho ou pós-massivo, circunscrevendo uma eventual classificação nessas categorias ao período de observação do texto e contexto musical. As generalizações em torno de tais categorias se tornam passíveis de questionamento, uma vez que as fronteiras entre elas são cada vez mais permeáveis. A viabilização de carreiras independentes pode ou não transitar por associações com setores ligados ao mainstream, pois o músico encontra mais alternativas de sustentabilidade, uma vez que a música é uma commodity, empregada na configuração de inúmeros produtos de entretenimento como ringtones, trilhas sonoras de games, propagandas, filmes e produtos televisivos, som ambiente de espaços públicos, além de ser conteúdo agregado a gadgets como aparelhos celulares e outros equipamentos eletro-eletrônicos. Critérios ideológicos e de fidelidade a uma proposta musical continuam balizando as decisões de músicos independentes no momento de estabelecerem ou não uma parceira com uma grande empresa, mas, uma vez atendidos esses pré-requisitos, que variam de acordo com cada projeto, as negociações contratuais podem determinar o não-fechamento do contrato com uma empresa do setor fonográfico e sim com uma major de outro ramo, como ocorreu com Mallu Magalhães.

\section{REFERÊNCIAS}

ANDERSON, Chris. A Cauda Longa: do mercado de massa para o mercado de nicho. Trad. Afonso Celso da Cunha. Rio de Janeiro: Elsevier, 2006.

ANTENORE, Armando. Revolucionária aos 16 anos. Revista Bravo, n.134. São Paulo: Editora Abril S.A., out. 2008.

CASTRO, Letícia de. Aos 16, Mallu Magalhães estréia disco como adulta. Folha de S. Paulo, 20/10/2008. São Paulo: Empresa Folha da Manhã, 2008. Disponível em: <http://www1.folha. uol.com.br/folha/ilustrada/ult 90u458008.shtml>. Acesso em: 07/06/2010.

HEBDIGE, Dick. Subculture: the meaning of style. Londres: Routledge, 2002.

LEMOS, André. Cidade e mobilidade. Telefones celulares, funções pós-massivas e territórios informacionais. Revista Intermídias, ano 5, n.9. Praia de Carapebus, Serra-ES, 2009. Disponível em: <http://www.intermidias.com/txt/ed\%/cidade\%20e\%20 mobilidade_ andrelemos. pdf $>$. Acesso em: 15/11/2009. 
MONTEIRO, Márcio; TROTTA, Felipe. O novo mainstream da música regional: axé, brega, reggae e forró eletrônico no Nordeste. Revista E-compós, v. 11, n. 2. Brasília, maio/ago 2008, p. 1-15. Disponível em: <http://www.compos.org.br/seer/index. php/ecompos /article/viewFile/295 /278>. Acesso em: 09/04/2010.

ROCHA, Everardo; PEREIRA, Cláudia; BALTHAZAR, Ana Carolina. Tempo livre é tempo útil: gadgets, entretenimento e juventude. Trabalho apresentado ao Grupo de Trabalho "Mídia e Entretenimento", do XIX Encontro da Compós, na PUC-Rio, Rio de Janeiro, RJ, jun. 2010. Disponível em: <http://compos.com.puc-rio.br/media/gt11_everardo_rocha_ claudia_pereira_ana_carolina_balthazar.pdf> Acesso em: 15/06/2010.

SÁ, Simone Pereira de. O CD morreu? Viva o Vinil!. In.: PERPÉTUO, Irineu Franco; SILVEIRA, Sergio Amadeu (Org.). O futuro da música depois da morte do CD. São Paulo: Momento Editorial, 2009, p. 49-72.

SHUKER, Roy. Vocabulário de música pop. Trad. Carlos Szlak. São Paulo: Hedra, 1999.

THÉBERGE, Paul. 'Conectados': la tecnologia e la musica popular. In: FRITH, Simon; STRAW, Will; STREET, John (Org.). La outra historia del rock. Trad. Jorge Conde. Barcelona: Ediciones Robinbook, 2006, p.25-52.

YÚDICE, George. Nuevas tecnologias, música y experiência. Barcelona: Gedisa, 2007.

Original recebido em: 05/02/2011

Aceito para publicação em: 12/09/11

Resumo sobre o autor:

Tatiana Rodrigues Lima é jornalista, professora da Faculdade Social da Bahia, desenvolve pesquisa de doutorado em Comunicação e Cultura Contemporâneas sobre música em plataformas digitais na Universidade Federal da Bahia, é mestre pelo mesmo programa (2007) e especialista em Gestão da Informação para Multimeios (2004). http://buscatextual.cnpq.br/buscatextual/visualizacv.do?id=K4782331U8 